\title{
Introduction: Older women and later life transitions in industrialized societies
}

As the populations of the industrialized nations have grown older, the Organisation for Economic Co-operation and Development (OECD) has shown there has been increasing concern among policymakers about the sustainability of social welfare systems and about the supply of labour as the so-called baby boomers exit the labour force (OECD, 1998, 2006). As noted by the OECD (2019a), between 2015 and 2050 the ratio of people aged 65 to those of working age is projected to double, which may act as a brake on global economic growth (Bloom et al., 2015). Consequently, it has been argued that 'it is extremely important for us to promote the employment of older people' (Seike et al., 2011, p. 46).

Where until quite recently public policy for older workers was pro-retirement it has now shifted to be pro-work (Shultz and Olson, 2012). A raft of public policy reforms and advocacy efforts focused on the prolongation of working lives have emerged internationally in the last two decades. Much of this may be characterized as lacking a strategic or holistic approach. It has sometimes had adverse or, at least, ambiguous outcomes for older people and has arguably failed to assist those from lower socio-economic groups, among others (Taylor, 2002; Taylor and Earl, 2016). It has also been argued that advocacy efforts that have purported to challenge labour market ageism have been undermined by approaches that misunderstand its nature and, ironically, have been firmly grounded in pejorative views of ageing and older people (Taylor, Earl and McLoughlin, 2016). As noted by Rowe and Kahn (2015, p. 595), in responding to issues of population ageing 'the task of redesigning organizations and institutions that developed to fit other times and conditions is formidable'.

Also apparent is the alignment of the present economic imperative for longer working lives with current gerontological thinking that seeks, firstly, to replace the deficit view of ageing with a more optimistic narrative (Foster and Walker, 2015; Katz and Calasanti, 2015) and, secondly, to challenge notions of increasing dependency at older ages (Rowe, 2015). Overlapping, competing frameworks have emerged that seek, for instance, to define 'active', 'productive' and 'successful' ageing (Foster and Walker, 2015; Hinterlong et al., 2001; Rowe and Kahn, 2015). Critics have, however, drawn parallels between the tenets of a neoliberal and entrepreneurial ideology and concepts these perspectives draw from, namely personal choice, lifestyle, fluidity, responsibility and agency (Katz and Calasanti, 2015; Moulaert and Biggs, 2013). Nevertheless, this builds on active ageing reforms described by the OECD (1998, p. 84) as 'those that remove these undesirable constraints on life course flexibility and that strengthen support to citizens in making life-time choices'.

According to Rowe and Kahn (1997) participation in productive activities, including informal help giving, volunteering and paid employment are essential for successful ageing. Critical to the concept is the notion that individuals can control the destiny of their own ageing 
(Katz and Calasanti, 2015). The idea of productive ageing grew out of responses to ageism and the view of older people as being unproductive (Hinterlong et al., 2001). Productive ageing has been described as referring to any activity that produces goods or services, or develops the capacity to do so, whether remunerated or not (Caro et al., 1993). Subsequently, active ageing emerged as a response to criticism that emphasizing productivity in the form of work could further marginalize those already disadvantaged in society (Estes and Mahakian, 2001). According to the World Health Organization (WHO) (2002, p. 12) the "word "active" refers to continuing participation in social, economic, cultural, spiritual and civic affairs, not just the ability to be physically active or to participate in the labour force'.

Across ageing nations, a key current policy objective concerning older people is the promotion of active ageing which Walker (2015, p. 20) defines as 'the optimisation of activities related to a wide range of endeavours'. Active ageing endorses activity and engagement in later years while recognizing valuable social and economic contributions made by older persons. Support for active ageing within communities should foster successful retirement for individuals. Active leisure may be argued to have a critical role in this process.

Emphasizing the importance of applying a broad definition of active ageing, Walker (2006, p. 84) argues that full participation and inclusion for older people 'suggests a general lifestyle strategy for the preservation of physical and mental health as people age rather than just trying to make them work longer'. However, as noted by Walker (2008, p. 85), 'for nearly a decade of a conception of active aging based on participation and wellbeing across the life course, the policy instruments still focus primarily on employment'. Foster and Walker (2019) have acknowledged that in reality policy on active ageing has come to be dominated by narrow economic or productivist perspectives and Moulaert and Biggs (2013) have gone so far as to describe the emergence of a work focused 'productivist version of legitimate ageing'. As a consequence, there is a need for more spadework concerned with widening conceptions of active ageing.

While active ageing narratives envisioning continuing opportunities reflect a holistic life courseoriented approach involving a broad focus beyond extended labour force participation, it is a more narrow productivist conceptualization that has been emphasized recently by major international organizations including the WHO, United Nations and European Union as well as national governments (Foster and Walker, 2015; Walker, 2008). Furthermore, definitions of active ageing in Europe and North America differ with the European conceptualization emphasizing health participation and wellbeing and the North American one prioritizing productivity (Walker, 2008).

Yet, ideas such as these are not clearly defined either. For example, in a contrast of public policy in Belgium and Québec, Moulaert and Paris (2013) found European notions of active ageing to be more reduced and limited to productivist notions than more comprehensive North American ones. A lack of consensus over definitions of the concept of active ageing risks it becoming 'positive political rhetoric' (Foster and Walker, 2013), or simply 'empty rhetoric' (Boudiny, 2013). Authors have suggested replacing the concept of active ageing due to its lack of attention to gendering of the life course and androcentric focus on the production of resources and services (Foster and Walker, 2013), or due to its narrow focus on expectations of ongoing physical activity in preference for a more culturally and socially inclusive concept, such as 'ageing well' (Ranzijn, 2010). 
Rather than abandoning it, we argue for broadening it. A broader conceptualization of active later life activities that encompasses all later life productive engagements may also emphasize socially useful, culturally inclusive and gender conscious, albeit unpaid, activities. For example, such a broader conceptualization might encompass a range of value-creating activities such as caring and volunteering that, arguably, are devalued traditionally as so-called 'women's work' located within the emotional sphere, domestic space and/or family context (Hochschild, 1997).

Transitions from working to retirement are being conceptualized as increasingly varied rather than a simplistic demarcation of life phases (Curl and Hokenstad, 2006). However, while there is a focus on a blending of paid working and retirement (Dropkin et al. 2016), it has been found across studies on post-retirement working that women less often return to work after self-identifying as retired (Pleau and Shauman, 2013). Moreover, women continue to juggle many different paid work and socially normed unpaid work roles, such as elder care, grandchild care and domestic duties, during both their working and post-work lives. Illustrating a 'process of the folding of the economy into society' proposed by Adkins (2012, pp. 621-622), this moves beyond historical divisions that locate women either in the family or the workplace to recognize their 'value-creating activities' beyond the workplace that generate 'productive moments' that are dispersed across society.

Nonetheless, current rhetoric, contextualized by ageing populations in many countries, seeks to portray participation in paid work in later life as an individual and social good (Borowski, et al., 2007; Millward and Brooke, 2007; Moen et al., 2016; Zacher, 2015). In fact, Walker (2008) and Moulaert and Biggs (2013) argue that the social contribution of older adults is increasingly restricted to work and work-like activity. In this context, an obvious government reaction to industrialized countries' ageing populations is to extend the span of working lives by removing a formal retirement age. Workers are being required to support themselves for a longer period before gaining eligibility to access state pensions and other retirement benefits such as private pensions and superannuation. But for a number of reasons, such as health status, many workers may lack the capacity to continue making a worthwhile, valuable or meaningful contribution (Taylor, 2011).

Decisions to retire, often considered well before stopping working, are contingent upon a range of factors associated with age, health, financial status, family responsibilities, social influences and cultural norms. As noted, labour force participation is currently viewed not simply as normative but more specifically as an individual and social good for both genders. In contrast to factors considered by older men, older women may face relatively more pressing financial and other gender-based constraints, such as elder care or grandparenting responsibilities and inadequate retirement savings generated by career interruptions, a higher prevalence of part-time work and lower average salaries (Australian Human Rights Commission, 2009). These factors may influence women's retirement decisions, including the timing of workforce withdrawal. Many single older women, for example, faced with insufficient post-work incomes, cannot afford to retire fully. Unlike their male counterparts, working women may have been subject to relatively lower wages and time-gaps from paid work due to child rearing and other caring responsibilities, which combine to reduce their ability to build for and plan a financially secure retirement (Everingham et al. , 2007; Byles et al., 2013).

While there may be financial incentives for women to extend their working lives, wellbeing and personal health issues may also be relevant. For instance, Henderson and Gibson 
(2013) note, in a review of women, gender and leisure research, that a link between women's active leisure and their physical and mental health is attracting increasing attention in the literature which has moved on from constraints women face to empowerment of women and from a one-model-fits-all approach to considering contextualized differences in a lack of opportunities.

The relationship between health status and working in one's later years is also contentious in the literature. According to Sahlgren (2013) being retired decreases physical, mental and self-assessed health, effects that increase as the number of years spent in retirement increases. Conversely, retirement may be precipitated through poor health stemming from a chronic condition or acute health crisis (Riach and Loretto, 2009). A number of empirical studies have considered the relationship between employment status and older workers' wellbeing. Staudinger et al. (2016, p. 286) in reviewing the literature conclude that "there seem to be converging evidence documenting the longer-term health benefits of employment for older adults'. By contrast, the evidence seems to be unequivocal that being unemployed adversely affects wellbeing (Nikolova and Graham, 2014). However, notions that retirement is necessarily detrimental to wellbeing and that any form of productive engagement is beneficial are questionable.

Forces contributing to the prolongation, or otherwise, of women's working lives have important individual consequences. Retirement provides time to continue pursuing or rebuild leisure interests and travel balanced by other activities that may include volunteering or caring for family members (Roberts, 2013). Yet retirement may not provide anticipated pleasures and benefits, even for relatively financially secure professional women. Price (2000), for example, found that the transition from a career to retirement was made difficult through women's loss of professional identity compounded by community and family perceptions that retired women were no longer able to meet difficult challenges or, conversely, that they had time available to meet any request. Retired women also lamented the loss of workplace social contact.

Placing work at the centre of what it means to age well is, however, potentially problematical in other ways. As Katz and Calasanti (2013) explain, as people get older the material and social resources accumulated over their life course become more salient. For example, those with job histories characterized by insecure or low-pay work have fewer benefits and less access to health care, with consequences for their ability to work and accumulate wealth. Thus, while advocates for prolonging working lives have identified a range of benefits for older people such as productive engagement, social support, intellectual challenge, and opportunities for physical activity (Roodin and Mendelson, 2013) this perspective on the ageing workforce may be criticized for naively assuming that all work is good, overlooking matters of job quality and security and how these factors shape patterns of work and retirement (Phillipson, 2019; Taylor and Earl, 2016). Moreover, it has been pointed out that many older people are not enthusiastically embracing this new work-centred identity for a successful later life (Earl and Taylor, 2017).

Alongside emerging policy interest in older workers is a substantial and growing body of research that has considered older workers' changing relationship with the labour market. Thus, Diversity Council Australia has reported that 'With life expectancy increasing to more than 84 years for women, and close to 70 per cent of older female workers rating their health as good or excellent, many older female workers are at their peak. For many this is translating into changing expectations about the trajectory of their working lives' (Tilly et al., 2013, p. 6). 
Also, of note is evidence that work plays a more decisive role in the timing of women's retirement than is the case for men (De Preter et al., 2013). This points to the need to pay attention to how age intersects with other sociological factors, including gender, race and socio-economic status (Katz and Calasanti, 2015; Loretto and Vickerstaff, 2015).

Yet while scholarly interest in the employment of older workers can be traced back to the 1950s and even earlier, and recently there has been a surge of research that has considered both demand for and supply of older workers, it is arguably the case that much research in the field of 'older workers' has tended to be gender blind and, in Australia at least, recent public policymaking in this area has largely ignored the particular needs of older women. These apparent gaps were the genesis of the Australian Research Council funded project Retiring Women: Understanding Older Female Work Life Transitions which commenced in 2009 and on which this monograph is based. The research set out to be deliberately provocative, not least in almost entirely focusing the data collection on older women's experiences, mostly of paid work and somewhat as job seekers and retirees, rather than to undertake a comparative study of women and men. Woman-centred research offers a number of advantages over gender analysis. The project focused on women only in order to determine how women conceptualize and experience retirement. Further, it explored women's experiences without reference to those of men and thus did not implicitly consider widespread androcentric norms as normative. Indeed, the analysis provokes a new conceptualization of retirement that unlike traditional notions is more inclusive and may apply to both genders.

The study explored women's experiences in order to develop policy and practice recommendations for structuring and enriching career and retirement transitions, specifically:

- Organizational responses to the challenge of managing women's labour market trajectories against a background of demographic and economic change.

- The meaning, centrality and role of paid work for older women.

- Older women's experiences of internal and external labour markets and how these affect retirement intentions and pathways.

- Lifestyle options women see as desirable and open to them, including caring roles and other perceived factors that influence and constrain work and lifestyle choices.

- The articulation between women's perceptions of their financial resources with work and retirement pathways.

- Barriers to remaining in or re-entering the labour market.

The data consisted of a large-scale quantitative survey of almost 3,000 women aged over 50 from two Australian industry superannuation funds, one representing the university sector and the other state and emergency services workers. This was followed by qualitative interviews with a subset of 84 of these women. Interviews with $97 \mathrm{HR}$ and other managers (58) and subject-matter experts (39) were also undertaken, but the decision was taken to exclude much of this material from this volume in order to devote as much space as possible to documenting the experiences of these older women. Findings from this aspect of the study have been reported elsewhere (Earl and Taylor, 2015; Earl et al., 2015; Taylor, Earl and Cannizzo, 2018). A key conclusion of this element of this research is that managers often do not know what the needs of older women workers are, indeed that they fall between the cracks of organizational policymaking, being overlooked both in terms of policymaking that is concerned with gender and also, to the extent that this occurs at all, that which is concerned with older workers. 
Additionally, workplace policies targeting older women are underdeveloped and managers often conflate potential with youthfulness. As such, older women are often not considered to be a resource worth investing in.

The project, and this monograph, had the objective of mapping older women's work and retirement transitions, with a particular focus on the latter. Chapter 1 contextualizes the labour market situation of older women, including international comparisons of labour force participation of older women workers. Chapter 2 reviews the relevant literature and also considers issues of public policy and older women. Chapter 3 introduces the research including the demographics of the sample and selected biographical vignettes of older women we interviewed. The following three chapters draw extensively on the quantitative data collected via the surveys of older women. Chapter 4 focuses on older women's experiences of working, considering the changing nature of work itself, examining issues of working hours, learning and education. Chapter 5 considers issues of transitions into the workforce, focusing on the drivers of, barriers to and facilitators in older women's lives and the increasing blurring of life stages from the perspective of women. Chapter 6 considers older women's expectations about retirement and their views concerning the transition to retirement (including casualization, precarity, under-employment, retirement intentions, lower superannuation and poverty, and impediments to living a fulfilling life). Chapter 7 draws on qualitative data collected from older women to explore how they experience retirement through a focus on leisure and other activities that highlight discourses of active and productive ageing. Chapter 8 extends the discussion of women's retirement transitions, considering issues of selves in transition from work to retirement, drawing on the qualitative data collected from among older women. Chapter 9 draws on interviews with stakeholders and human resource practitioners to outline some of the organizational and public policy issues that compound the complexities of older women's portfolio careers in retirement. The monograph concludes in Chapter 10 with a discussion of the implications of the study for research, advocacy and public policy, with recommendations for each. 